\title{
Higher nuclear EGFR expression is a better predictor of survival in rectal cancer patients following neoadjuvant chemoradiotherapy than cytoplasmic EGFR expression
}

\author{
CHING-CHIEH YANG ${ }^{1-3}$, LI-CHING LIN $^{1}$, YU-WEI LIN ${ }^{1,2}$, YU-FENG TIAN $^{4,5}$, \\ CHEN-YI LIN ${ }^{6}$, MING-JEN SHEU ${ }^{6}$, CHIEN-FENG LI ${ }^{7-9 *}$ and MING-HONG TAI ${ }^{2,10^{*}}$
}

${ }^{1}$ Department of Radiation Oncology, Chi-Mei Medical Center, Tainan 71069; ${ }^{2}$ Institute of Biomedical Sciences, National Sun Yat-Sen University, Kaohsiung 80424; ${ }^{3}$ Department of Pharmacy, Chia-Nan University of Pharmacy and Science, Tainan $71745 ;{ }^{4}$ Division of General Surgery, Department of Surgery, Chi Mei Medical Center, Tainan 71069;

${ }^{5}$ Department of Health and Nutrition, Chia Nan University of Pharmacy and Science, Tainan 71745 ; ${ }^{6}$ Division of Gastroenterology and Hepatology, Department of Internal Medicine; ${ }^{7}$ Department of Pathology, Chi Mei Medical Center,

Tainan 71069; ${ }^{8}$ National Institute of Cancer Research, National Health Research Institutes,Tainan 70456;

${ }^{9}$ Department of Biotechnology, Southern Taiwan University of Science and Technology, Tainan 71005;

${ }^{10}$ Center for Neuroscience, National Sun Yat-Sen University, Kaohsiung 80424, Taiwan, R.O.C.

Received March 12, 2018; Accepted November 15, 2018

DOI: $10.3892 / 01.2018 .9756$

\begin{abstract}
The aim of the present study was to investigate the prognostic value of cytoplasmic (-C) and nuclear epidermal growth factor receptor (EGFR-N) expression in rectal cancer patients following neoadjuvant concurrent chemoradiotherapy (CCRT). A total of 172 newly diagnosed rectal cancer patients post-neoadjuvant CCRT and curative surgery, treated between January 1998 to December 2008, were included. Pathological tissues used for evaluation were biopsy specimens obtained prior to CCRT, and specimens collected at
\end{abstract}

Correspondence to: Dr Chien-Feng Li, Department of Pathology, Chi Mei Medical Center, B2, 901 Zhonghua Road, Yongkang, Tainan 71069, Taiwan, R.O.C.

E-mail: angelo.p@yahoo.com.tw

Professor Ming-Hong Tai, Institute of Biomedical Sciences, National Sun Yat-Sen University, 70 Lien-Hai Road, Kaohsiung 80424, Taiwan, R.O.C.

E-mail: minghongtai@gmail.com

*Contributed equally

Abbreviations: CCRT, concurrent chemoradiotherapy; AJCC, American Joint Committee on Cancer; TNM, tumor-node-metastasis; EGFR, epidermal growth factor receptor; EGFR-C, cytoplasmic EGFR; EGFR-N, nuclear EGFR; Pre-Tx, pre-treatment; Post-Tx, post-treatment; DSS, disease-specific survival; LRFS, local-recurrence-free survival; MeFS, metastases-free survival; HR, hazard ratio; $\mathrm{CI}$, confidence interval

Key words: epidermal growth factor receptor, nuclear, rectal cancer, chemoradiotherapy, survival analysis surgery. EGFR expression in the nucleus and cytoplasm was assessed by immunohistochemistry tests. An intensity of $3+$ EGFR reactivity in the cytoplasm (and/or membrane) of tumor cells was defined as overexpression of EGFR-C. The cutoff percentage of immunoreactive tumor cells for EGFR-N overexpression was 50\%. Expression levels of EGFR-C and EGFR-N were further analyzed by clinicopathological features for 5-year survival disease-specific survival (DSS), local recurrence-free survival (LRFS) and metastasis-free survival (MeFS). The results revealed that 20.9 and $23.3 \%$ of the cohort had high EGFR-N and EGFR-C expression, respectively. EGFR-N overexpression was significantly associated with advanced pre-treatment tumor stage (T3 and 4; $\mathrm{P}=0.017$ ) and post-treatment tumor stage (T3 and 4; $\mathrm{P}<0.001)$. In univariate analysis, EGFR-N overexpression was significantly associated with poorer DSS $(\mathrm{P}=0.0005)$, MeFS $(\mathrm{P}=0.0182)$, and LRFS $(\mathrm{P}=0.0014)$. Furthermore, it remained an independent prognosticator of worse DSS $[\mathrm{P}=0.007$, hazard ratio $(\mathrm{HR})=2.755]$ and $\mathrm{LRFS}(\mathrm{P}=0.0164, \mathrm{HR}=3.026)$ in multivariate analysis. Overexpression of EGFR-N, and not EGFR-C, may help identify rectal cancer patients who have an increased risk of local recurrence and poor survival following neoadjuvant CCRT.

\section{Introduction}

Rectal cancer is an increasing, and important disease worldwide (1). For patients with American Joint Committee on Cancer (AJCC) stage II or III disease, neoadjuvant concurrent chemoradiotherapy (CCRT) followed by radical proctectomy remains the preferred therapy as it has been shown to provide better local control, greater anal preservation, and lesser toxicity (2). However, up to $10-20 \%$ of these patients will eventually develop local or distal disease recurrence (3). 
Rectal cancer post neoadjuvant CCRT or not are all staged by using the AJCC tumor-node-metastasis (TNM) staging system, and further adjuvant treatment is recommended. There is no modification of staging for patients who receive neoadjuvant CCRT. Prediction of prognosis using TNM staging is suboptimal, and survival of patients with the same stage disease can vary markedly. Therefore, additional prognostic biomarkers to aid in risk stratification and identify patients who may benefit from more intensive treatment may help to improve outcomes.

Epidermal growth factor receptor (EGFR) is a transmembrane glycoprotein that belongs to the HER family of receptor tyrosine kinases, and promotes multiple signaling cascades for cellular survival, such as RAS/MAPK, PI3K/Akt, Stat, and Src (4). Overexpression of cytoplasmic EGFR (EGFR-C) is associated with tumor differentiation, proliferation, and migration, and has been extensively studied as the most important cancer molecular target in recent decades $(5,6)$. Recently, studies have reported that EGFR family members can be transported from the plasma membrane to the nucleus, and regulate target genes involved in cell proliferation and angiogenesis $(7,8)$. The prognostic significance of nuclear EGFR (EGFR-N) has been demonstrated, and is highly associated with tumor progression and worse overall survival (OS) $(9,10)$. It has also been shown to be associated with enhanced resistance to systemic and radiation therapy (7). Therefore, overexpression of EGFR-N is frequently a poor prognostic factor. However, little is known about the relevance of EGFR-N in rectal cancer patients treated with neoadjuvant CCRT.

The aim of this study was to evaluate the clinical correlates of EGFR-C and EGFR-N expression in rectal cancer patients after neoadjuvant CCRT, and also to compare the impact of EGFR-N and EGFR-C expression on prognosis.

\section{Materials and methods}

Ethics statement. The present study was reviewed and approved by the Institutional Review Board of Chi-Mei Medical Center in Taiwan (Tainan, Taiwan; IRB, CMFHR10501-008). The requirement for informed consent was waived as all identifying information was removed from the dataset prior to analysis.

Patient demographic characteristics and tumor specimens. This retrospective study was performed on formalin-fixed paraffin-embedded (FFPE) tissue specimens from 172 newly diagnosed rectal adenocarcinoma patients treated at Chi-Mei Medical Center between 1998 and 2004. The data was collected and analyzed in February 2014. All patients received preoperative 5-fluorouracil-based chemotherapy concomitant with radiotherapy (45-50 Gy), followed by radical proctectomy with total mesorectal excision. The clinical stage was determined by endoscopic ultrasound (EUS), abdominal computed tomography $(\mathrm{CT})$, or magnetic resonance imaging (MRI) findings. Adjuvant systemic chemotherapy was given if the post-treatment (Post-Tx) tumor or nodal status was beyond T3 or N1. All patients were regularly monitored after diagnosis until death or last follow-up. Patients who had a previous cancer history, distal metastasis at diagnosis, or were unable to complete a full course of CCRT were excluded. The histopathological parameters were reviewed by our pathologist (Dr. Li) who was blind to the patients' clinical data.
The data extracted from the medical records included the date of diagnosis, age, sex, clinical TNM stage, pathological characteristics such as lymphovascular and perineural invasion, chemotherapy regimen and timing, and cause of death. All patients were re-staged and re-graded according to the 7th edition of the AJCC staging system, and World Health Organization (WHO) classification of Tumors of the Colon and Rectum. The primary endpoints were 5-year disease-specific survival (DSS), local recurrent-free survival (LRFS), and metastases-free survival (MeFS) rates. Deaths due to cancer were defined as valid events, and deaths secondary to other causes were censored.

Immunohistochemistry analysis. Immunohistochemistry of tissue microarray (TMA) slides and whole sections were prepared as previously described (11). Briefly, tissue sections from Pre-Tx rectal tumor biopsies were deparaffinized and rehydrated for EGFR immunostaining. Overexpression of EGFR-C was defined as an intensity of 3+ EGFR reactivity seen in the cytoplasm (and/or membrane) of tumor cells (12). To define overexpression, the cutoff percentage of immunoreactive tumor cells was $50 \%$ for EGFR-N in this analysis (13).

Statistical analysis. The results are presented as the mean \pm standard deviation. All statistical analyses and graphics were performed using IBM SPSS statistical software for Windows, v14.0 (SPSS, Inc., Chicago, IL, USA). P<0.05 was considered to indicate a statistically significant difference. Examination of the associations of EGFR expression with clinicopathological features was conducted using the chi-square test. The Kaplan-Meier method was used to analyze the cumulative 5-year DSS, LRFS, and MeFS rates, and rates were compared using the log-rank test to evaluate prognostic differences between subgroups. The primary event was defined as disease-specific mortality, and survival curves were calculated from the date of diagnosis. Those parameters that demonstrated prognostic significance in the univariate analysis were input into the Cox multivariate regression analysis.

\section{Results}

Patient demographic and clinical characteristics are summarized in Table I. A total of 172 rectal cancer patients who underwent neoadjuvant CCRT and radical proctectomy with total mesorectal excision from January 1998 to December 2008 were included. The median age was 63 years (range: 22-88 years). The percentages of patients with initial stage I, II, and III disease were 41.9, 29.9, and $28.1 \%$ and all stage II, III patients received adjuvant chemotherapy Fifteen $(8.7 \%)$ patients presented with lymphovascular invasion, and 5 $(2.9 \%)$ with perineural invasion.

The results of EGFR immunostaining to investigate EGFR expression in the cytoplasm and the nucleus of rectal tumor tissues are shown in Fig. 1. Of the patients, 20.9\% had EGFR-N overexpression, 23.3\% EGFR-C overexpression and 5.2\% have both high EGFR-N and high EGFR-C expression. EGFR-N overexpression was significantly related to advanced pre-Tx tumor T-stage (T3, 4; $\mathrm{P}=0.017)$ and post-Tx tumor T-stage (T3, 4; P<0.001). EGFR-C overexpression was significantly related to pre-Tx tumor T-stage $(\mathrm{T} 3,4 ; \mathrm{P}=0.013)$, post-Tx tumor 
Table I. Associations and comparisons between Nuclear/Cytoplasmic epidermal growth factor receptor expression and clinicopathological factors in 172 rectal cancer patients.

\begin{tabular}{|c|c|c|c|c|c|c|c|c|}
\hline \multirow[b]{2}{*}{ Parameter } & \multirow[b]{2}{*}{ Variable } & \multirow[b]{2}{*}{ No. of cases } & \multicolumn{2}{|c|}{ EGFR-N (n) } & \multirow[b]{2}{*}{ P-value } & \multicolumn{2}{|c|}{ EGFR-C (n) } & \multirow[b]{2}{*}{ P-value } \\
\hline & & & Low Exp. & High Exp. & & Low Exp. & High Exp. & \\
\hline \multirow[t]{2}{*}{ Gender } & Male & 108 & 84 & 24 & 0.0768 & 82 & 26 & 0.741 \\
\hline & Female & 64 & 51 & 13 & & 50 & 14 & \\
\hline \multirow[t]{2}{*}{ Age } & $<60$ & 65 & 51 & 14 & 0.995 & 49 & 16 & 0.742 \\
\hline & $\geq 60$ & 107 & 84 & 23 & & 83 & 24 & \\
\hline \multirow[t]{2}{*}{ Pre-Tx tumor status (Pre-T) } & $\mathrm{T} 1-\mathrm{T} 2$ & 81 & 70 & 11 & $0.017^{\mathrm{a}}$ & 69 & 12 & $0.013^{\mathrm{a}}$ \\
\hline & T3-T4 & 91 & 65 & 26 & & 63 & 28 & \\
\hline \multirow[t]{2}{*}{ Pre-Tx nodal status (Pre-N) } & NO & 125 & 101 & 24 & 0.229 & 103 & 22 & $0.004^{b}$ \\
\hline & $\mathrm{N} 1-\mathrm{N} 2$ & 47 & 34 & 13 & & 29 & 18 & \\
\hline \multirow[t]{2}{*}{ Post-Tx tumor status (Post-T) } & $\mathrm{T} 1-\mathrm{T} 2$ & 86 & 77 & 9 & $<0.001^{\mathrm{c}}$ & 71 & 15 & 0.071 \\
\hline & T3-T4 & 86 & 58 & 28 & & 65 & 25 & \\
\hline \multirow[t]{2}{*}{ Post-Tx nodal status (Post-N) } & No & 123 & 99 & 24 & 0.312 & 99 & 24 & 0.066 \\
\hline & $\mathrm{N} 1-\mathrm{N} 2$ & 49 & 36 & 13 & & 33 & 16 & \\
\hline \multirow[t]{2}{*}{ Lymphovascular invasion } & Absent & 157 & 123 & 34 & 0.881 & 124 & 33 & $0.025^{\mathrm{a}}$ \\
\hline & Present & 15 & 12 & 3 & & 8 & 7 & \\
\hline \multirow[t]{2}{*}{ Perineural invasion } & Absent & 167 & 131 & 36 & 0.933 & 130 & 37 & $0.048^{\mathrm{a}}$ \\
\hline & Present & 5 & 4 & 1 & & 2 & 3 & \\
\hline \multirow[t]{2}{*}{ Cytoplasmic EGFR expression } & Low Exp. & 132 & 105 & 27 & 0.540 & $\mathrm{n} / \mathrm{a}$ & $\mathrm{n} / \mathrm{a}$ & $\mathrm{n} / \mathrm{a}$ \\
\hline & High Exp. & 40 & 30 & 10 & & $\mathrm{n} / \mathrm{a}$ & $\mathrm{n} / \mathrm{a}$ & \\
\hline
\end{tabular}

${ }^{\mathrm{a}} \mathrm{P}<0.05 ;{ }^{\mathrm{b}} \mathrm{P}<0.01 ;{ }^{\mathrm{c}} \mathrm{P}<0.001$. EGFR-C, cytoplasmic epidermal growth factor receptor; EGFR-N, nuclear epidermal growth factor receptor; Pre-Tx, pre-treatment; Post-Tx, post-treatment; Exp., expression; n/a, not applicable.
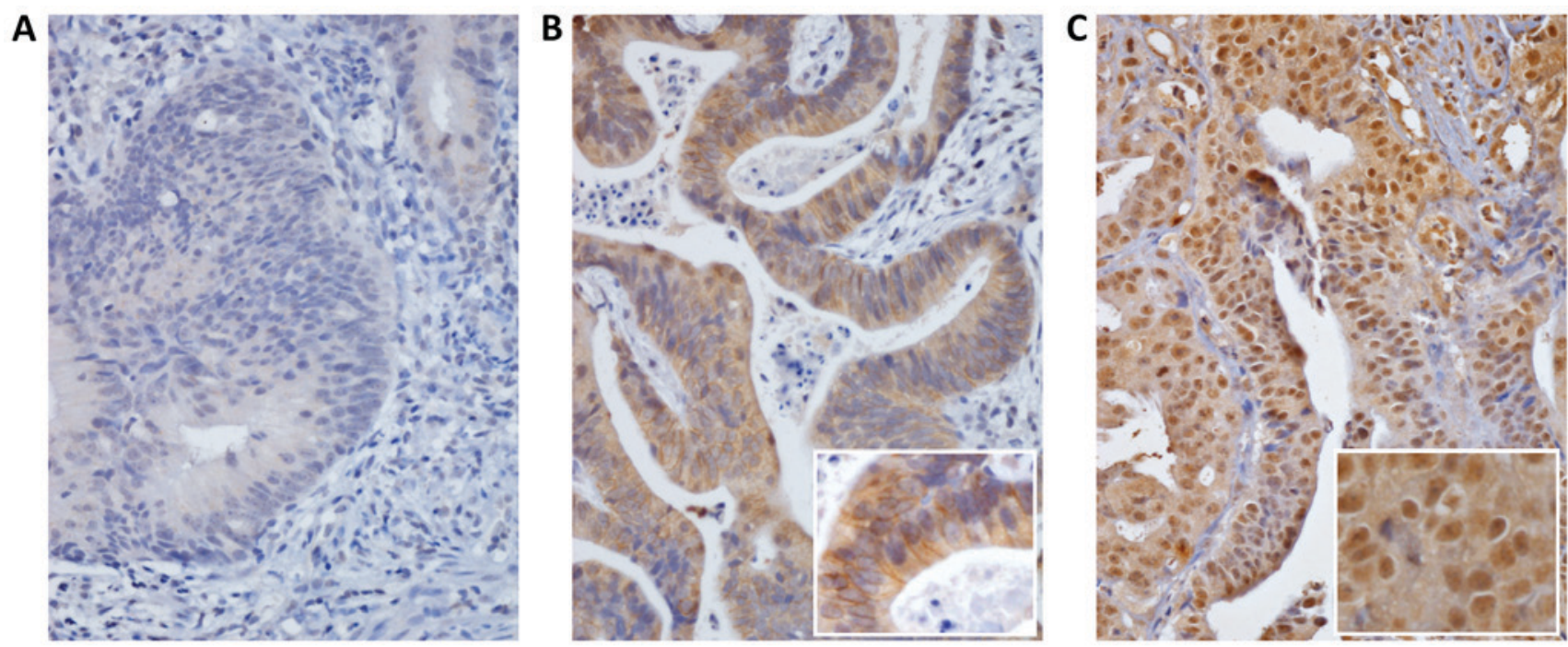

Figure 1. EGFR-C and EGFR-N expression by staining intensity using immunohistochemistry in rectal cancer tissue microarray. (A) EGFR low expression (magnification, x400); (B) EGFR-C high expression; (magnification: Main, x400; insert, x600) and (C) EGFR-N high expression (magnification: Main, x400; insert, x600). EGFR-C, cytoplasmic epidermal growth factor receptor; EGFR-N, nuclear epidermal growth factor receptor.

T-stage (T3, 4; $\mathrm{P}=0.004)$, lymphovascular invasion $(\mathrm{P}=0.025)$, and perineural invasion $(\mathrm{P}=0.048)$.

Univariate and multivariate survival analyses for factors predicting survival. In univariate analyses (Table II), post-Tx tumor status and nuclear EGFR expression were significantly correlated with poorer 5-year DSS, LRFS, and MeFS rate (all, $\mathrm{P}<0.05)$.

Pre-Tx nodal status, lymphovascular invasion, and perineural invasion were negatively associated with 5-year DSS and LRFS (all, $\mathrm{P}<0.05)$. Pre-Tx tumor status was significantly associated with poorer 5-year DSS only $(\mathrm{P}=0.0484)$. Multivariate analyses 
Table II. Univariate log-rank analysis for important clinicopathological variables and epidermal growth factor receptor expression.

\begin{tabular}{|c|c|c|c|c|c|c|c|c|}
\hline \multirow[b]{2}{*}{ Parameter } & \multirow[b]{2}{*}{ Variable } & \multirow[b]{2}{*}{$\begin{array}{l}\text { No. of } \\
\text { cases }\end{array}$} & \multicolumn{2}{|c|}{ DSS } & \multicolumn{2}{|c|}{ LRFS } & \multicolumn{2}{|c|}{ MeFS } \\
\hline & & & $\begin{array}{l}\text { No. of } \\
\text { events }\end{array}$ & P-value & $\begin{array}{l}\text { No. of } \\
\text { events }\end{array}$ & P-value & $\begin{array}{l}\text { No. of } \\
\text { events }\end{array}$ & P-value \\
\hline \multirow[t]{2}{*}{ Gender } & Male & 108 & 20 & 0.6027 & 5 & 0.3096 & 14 & 0.1047 \\
\hline & Female & 64 & 11 & & 17 & & 15 & \\
\hline \multirow[t]{2}{*}{ Age } & $<60$ & 65 & 13 & 0.3259 & 7 & 0.7575 & 17 & $0.0052^{\mathrm{b}}$ \\
\hline & $\geq 60$ & 107 & 18 & & 15 & & 12 & \\
\hline \multirow[t]{2}{*}{ Pre-Tx tumor status (Pre-T) } & $\mathrm{T} 1-\mathrm{T} 2$ & 81 & 10 & $0.0484^{\mathrm{a}}$ & 7 & 0.0836 & 10 & 0.1288 \\
\hline & $\mathrm{T} 3-\mathrm{T} 4$ & 91 & 21 & & 15 & & 19 & \\
\hline \multirow[t]{2}{*}{ Pre-Tx nodal status (Pre-N) } & N0 & 125 & 19 & $0.0059^{b}$ & 12 & $0.0025^{\mathrm{b}}$ & 18 & 0.0866 \\
\hline & $\mathrm{N} 1-\mathrm{N} 2$ & 47 & 21 & & 10 & & 11 & \\
\hline \multirow[t]{2}{*}{ Post-Tx tumor status (Post-T) } & $\mathrm{T} 1-\mathrm{T} 2$ & 86 & 12 & $0.0006^{\mathrm{c}}$ & 5 & $0.0056^{\mathrm{b}}$ & 8 & $0.0123^{\mathrm{a}}$ \\
\hline & $\mathrm{T} 3-\mathrm{T} 4$ & 86 & 34 & & 17 & & 21 & \\
\hline \multirow[t]{2}{*}{ Post-Tx nodal status (Post-N) } & No & 123 & 31 & 0.3442 & 15 & 0.6267 & 20 & 0.8403 \\
\hline & $\mathrm{N} 1-\mathrm{N} 2$ & 49 & 15 & & 7 & & 9 & \\
\hline \multirow[t]{2}{*}{ Lymphovascular invasion } & Absent & 157 & 38 & $0.0107^{\mathrm{a}}$ & 17 & $0.0023^{\mathrm{b}}$ & 26 & 0.7236 \\
\hline & Present & 15 & 8 & & 5 & & 3 & \\
\hline \multirow[t]{2}{*}{ Perineural invasion } & Absent & 167 & 43 & $0.0297^{\mathrm{a}}$ & 20 & $0.0083^{\mathrm{b}}$ & 28 & 0.8157 \\
\hline & Present & 5 & 3 & & 2 & & 1 & \\
\hline \multirow[t]{2}{*}{ Cytoplasmic EGFR expression } & Low Exp. & 132 & 33 & 0.6480 & 16 & 0.6884 & 20 & 0.3363 \\
\hline & High Exp. & 40 & 13 & & 6 & & 9 & \\
\hline \multirow[t]{2}{*}{ Nuclear EGFR expression } & Low Exp. & 135 & 28 & $0.0005^{\mathrm{c}}$ & 12 & $0.0014^{\mathrm{b}}$ & 18 & $0.0182^{\mathrm{a}}$ \\
\hline & High Exp. & 37 & 18 & & 10 & & 11 & \\
\hline
\end{tabular}

${ }^{\mathrm{a}} \mathrm{P}<0.05 ;{ }^{\mathrm{b}} \mathrm{P}<0.01 ;{ }^{\mathrm{c}} \mathrm{P}<0.001$. EGFR-C, cytoplasmic epidermal growth factor receptor; EGFR-N, nuclear epidermal growth factor receptor; Pre-Tx, pre-treatment; Post-Tx, post-treatment; DSS, disease-specific survival; LRFS, local-recurrence-free survival; MeFS, metastases-free survival; Exp., expression.

results are shown in Table III. EGFR-N, but not EGFR-C, was an independent prognostic factor for 5-year DSS (hazard ratio $[\mathrm{HR}]=2.755,95 \%$ confidence interval $[\mathrm{CI}]: 1.313-5.783)$ and LRFS (HR=3.026, 95\% CI: 1.224-7.281), but not for MeFS $(\mathrm{HR}=1.853$, 95\% CI: 0.852-4.032). Pre-Tx nodal status and post-Tx tumor status were independent prognostic factors for 5-year DSS only (HR=2.640, 95\% CI: 1.317-5.290; $\mathrm{HR}=2.210$, 95\% CI: 1.084-4.503, respectively).

EGFR-N overexpression as an independent prognostic factor. Overexpression of EGFR-N, but not EGFR-C, was significantly correlated with poor DSS, LRFS, and MeFS in univariate analyses (all, P<0.05) (Table II; Fig. 2). Higher expression of EGFR-N remained an independent predictor of worse DSS and LRFS in multivariate analyses, as shown in Table III $(\mathrm{HR}=2.755$, 95\% CI: $1.3137-5.783 ; \mathrm{HR}=3.026,95 \%$ CI: 1.224-7.281, respectively).

\section{Discussion}

There have been great advances in the treatment of rectal cancer in recent decades, and neoadjuvant CCRT followed by radical proctectomy has become primary treatment. However, the long-term survival of rectal cancer patients has remained stagnant. Therefore, it is necessary to find effective predictive biomarkers to stratify high-risk patients for more intensive therapy. In this study, we demonstrated that high expression of EGFR-N, but not EGFR-C, was correlated with aggressive tumor behavior and poor outcome. These results suggest that EGFR-N may be useful for outcome prediction in rectal cancer patients after CCRT, and may possibly be a potential therapeutic target.

Molecular methods usually provide reliable information for cancer patients. However, studies that have evaluated prognostic biological markers for rectal cancer have yielded inconclusive results $(14,15)$. A variety of studies have suggested that overexpression of EGFR was positively correlated with aggressive tumor behavior and poor prognosis in colorectal cancer $(12,16,17)$. But, there was considerable discrepancy in the frequency and distribution of EGFR expression in previous immunohistochemical studies $(18,19)$. Many of these studies provided speculative information on the association of protein expression and clinicopathological features. Furthermore, in clinical trials evaluating the efficacy of cetuximab, treatment response was not related to the level of EGFR expression; many patients with colorectal cancer expressing EGFR failed to respond to treatment, and those with EGFR negative tumors responded to therapy. A possible reason that EGFR levels are a poor predictor of response to anti-EGFR therapies is disparity between the form or epitope of EGFR detected by immunohistochemistry and the one targeted by anti-EGFR monoclonal antibodies (7). 


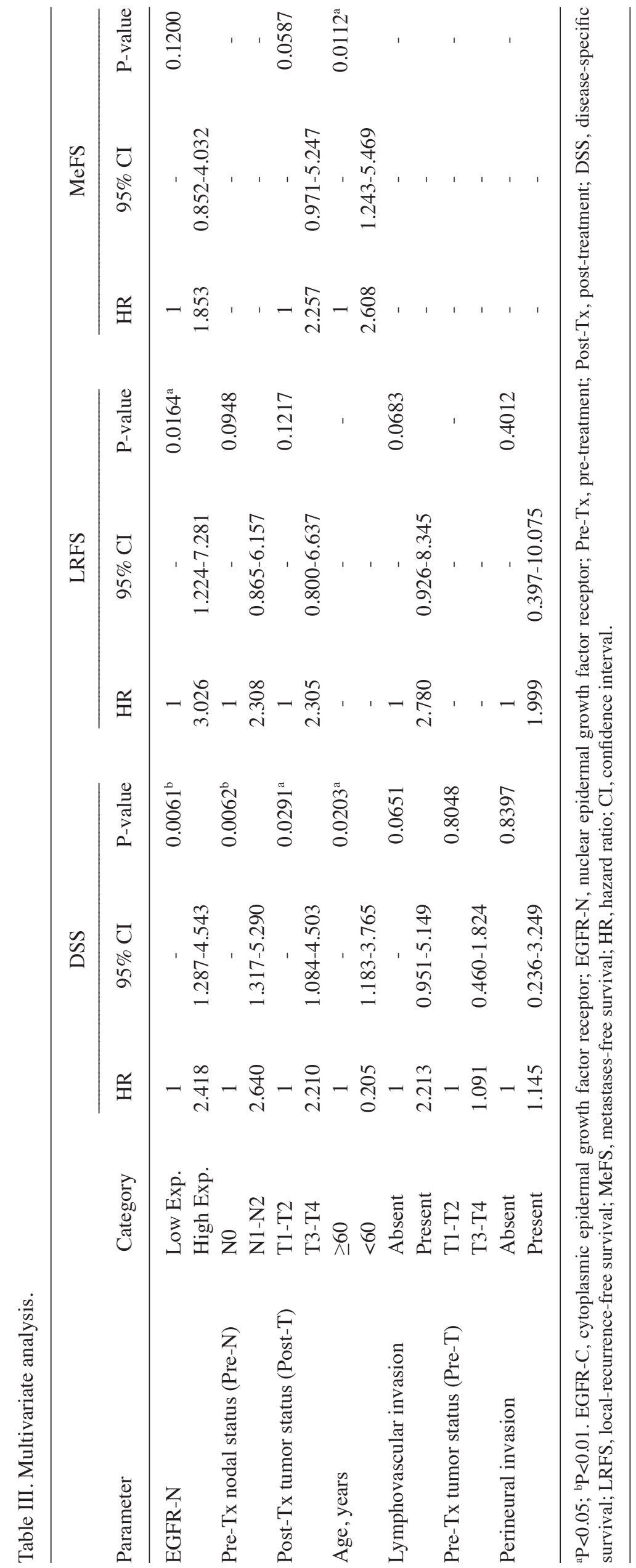


A

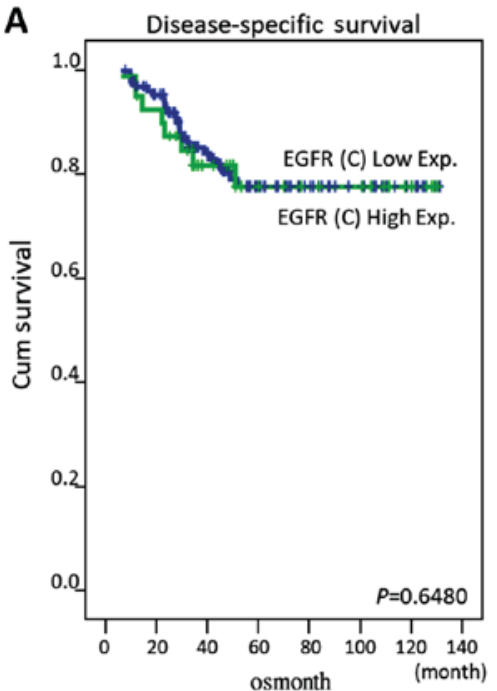

D

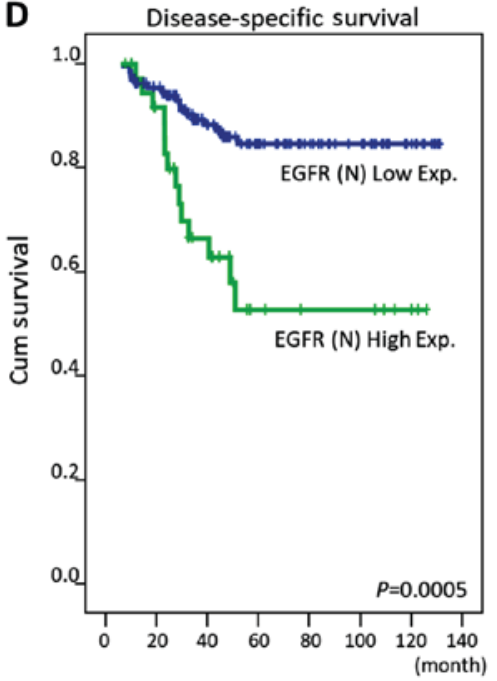

B

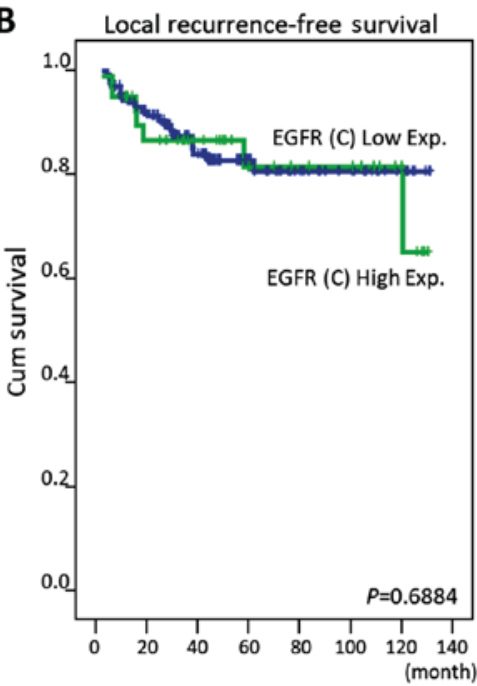

$\mathbf{E}$

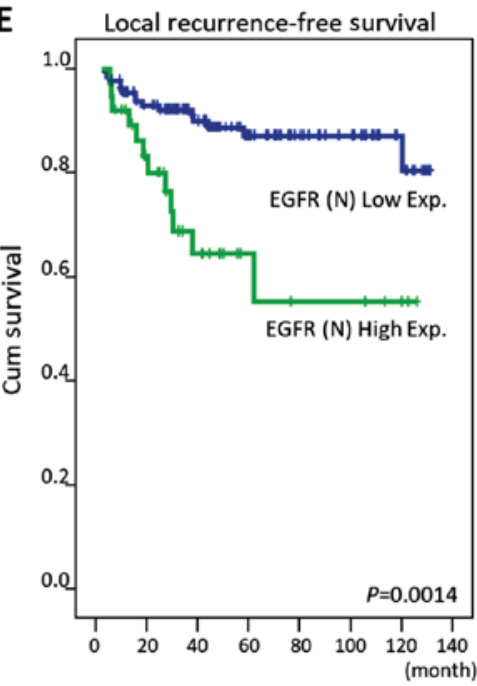

C
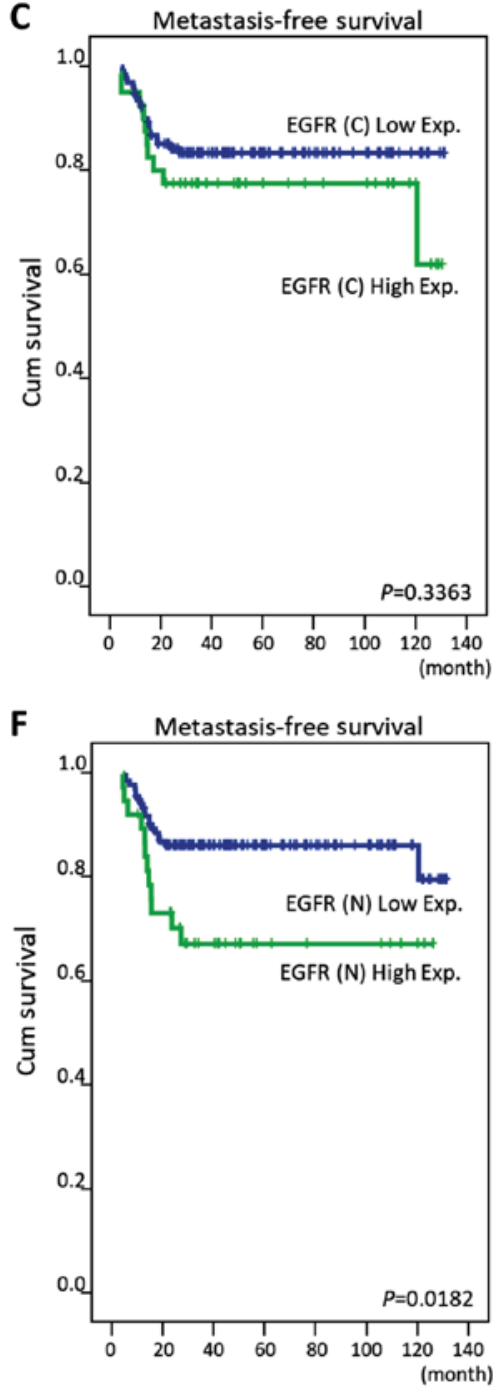

Figure 2. Kaplan-Meier analysis of the 5-year disease-specific survival, local recurrence-free survival and metastasis-free survival for rectal cancer patients with (A-C) EGFR-C and (D-F) EGFR-N expression. EGFR-C, cytoplasmic epidermal growth factor receptor; EGFR-N, nuclear epidermal growth factor receptor.

Recent evidence has suggested that EGFR can translocate to the nucleus (7). After activation, the nuclear translocation of EGFR has been shown to be dependent on phosphorylation events by many intracellular kinases such as SRC family and AKT (9). The nuclear transport of EGFR is guided by COPI-mediated vesicular trafficking from the Golgi to the endoplasmic reticulum (ER) (20). After being shuttled into the ER membrane, EGFR and importin $\beta 1$ interface in the nuclear pore complex, and shuttle EGFR from the outer to the inner nuclear membrane. Once in the nucleus, the function of EGFR is widely different from its plasma membrane bound counterpart. EGFR-N is involved in many cellular signaling pathways such as cell proliferation, tumor behavior, DNA synthesis, and DNA repair (21-24). EGFR-N also plays a functional role in the response to molecular therapeutic agents, and has been linked to poor prognosis in a variety of malignancies $(9,10,25)$. Hadzisejdic et al (10), reported that higher EGFR-N staining was associated with shorter OS in breast cancer patients. Overexpression of EGFR-N carried a 3.4-times greater mortality risk as compared to EGFR-N negative patients $(\mathrm{HR}=3.402 ; \mathrm{P}=0.0026)$. Hoshino et al $(25)$, also demonstrated that EGFR-N was associated with an increase in the malignant potential of esophageal squamous cell carcinoma that may affect the prognosis these patients. These intriguing findings emphasize the relevance of evaluating both EGFR-C and EGFR-N expression in colorectal cancer in order to provide additional independent prognostic information.

Our results showed that EGFR-N overexpression was significantly related to advanced pre-Tx tumor T-stage (T3, 4; $\mathrm{P}=0.017)$ and post-Tx tumor $\mathrm{T}$-stage $(\mathrm{T} 3,4 ; \mathrm{P}<0.001)$. In multivariate survival analysis, EGFR-N expression was also correlated with worse 5-year DSS and LRFS. These findings are different than those of prior studies where EGFR-C was associated with aggressive tumor behavior and poor outcomes $(17,19)$. Similar to our study, Doger et al $(16)$ evaluated 60 colon tumor specimens and reported that EGFR-C expression did not predict lymph nodes metastasis or survival. Moreover, EGFR-N overexpression was significantly associated with worse 5-year DSS ( $\mathrm{HR}=2.755$, $\mathrm{P}=0.007)$ and LRFS $(\mathrm{HR}=3.026, \mathrm{P}=0.0164)$, but not MeFS $(\mathrm{HR}=1.85, \mathrm{P}=0.12)$. The possible reasons for these findings may be that nuclear translocation of EGFR decreases 
cell survival, and is associated with enhanced resistance to radiation and chemotherapy (7). EGFR-N is correlated with increased DNA-dependent protein kinase (DNA-PK) activity, which plays an essential role in DNA damage repair and radioresistance (26). Thus, the overexpression of EGFR-N in rectal cancers could contribute to the identification of patients who have an increased risk of local recurrences and poor outcomes after neoadjuvant CCRT.

The present study has some limitations. First, the number of patients was relatively small, and the findings should be verified by larger-scale studies. Second, our study cohort included some early-stage rectal cancer patients because of the intention of organ preservation via neoadjuvant CCRT. Further studies focused on locally advanced rectal cancer should be performed. Finally, our results are applicable to only patients with non-metastatic rectal cancer who undergo CCRT.

In summary, the present study revealed that overexpression of EGFR-N, but not EGFR-C, may help identify and stratify high-risk patients after neoadjuvant CCRT. The strong inverse correlation with DFS and LFRS suggested that EGFR-N may be a potential prognostic biomarker and promising therapeutic target.

\section{Acknowledgements}

Not applicable.

\section{Funding}

The study was supported from the Health and Welfare surcharge of tobacco products (MOHW107-TDU-B-212-114020, WanFang Hospital, Chi-Mei Medical Center, and Hualien Tzu-Chi Hospital Joing Cancer Center Grant-Focus on Colon Cancer Research).

\section{Availability of data and materials}

The datasets used and/or analyzed during the present study are available from the corresponding author on reasonable request.

\section{Authors' contributions}

CY, LL, YL, YT, CYL, MS, CFL and MT conceived and designed the experiments. CY, LL and CFL participated in the design of the study and performed the statistical analysis. CY, LL, CFL and MT drafted the manuscript. All authors read and approved the final manuscript.

\section{Ethics approval and consent to participate}

The present study was reviewed and approved by the Institutional Review Board of Chi-Mei Medical Center in Taiwan (Tainan, Taiwan; IRB, CMFHR10501-008). The requirement for informed consent was waived as all identifying information was removed from the dataset prior to analysis.

\section{Patient consent for publication}

Not applicable.

\section{Competing interests}

The authors declare that they have no competing interests.

\section{References}

1. Siegel RL, Miller KD and Jemal A: Cancer statistics, 2016. CA Cancer J Clin 66: 7-30, 2016.

2. Sauer R, Becker H, Hohenberger W, Rödel C, Wittekind C, Fietkau R, Martus P, Tschmelitsch J, Hager E, Hess CF, et al: Preoperative versus postoperative chemoradiotherapy for rectal cancer. N Engl J Med 351: 1731-1740, 2004.

3. van den Brink M, Stiggelbout AM, van den Hout WB, Kievit J, Klein Kranenbarg E, Marijnen CA, Nagtegaal ID, Rutten HJ, Wiggers T and van de Velde CJ: Clinical nature and prognosis of locally recurrent rectal cancer after total mesorectal excision with or without preoperative radiotherapy. J Clin Oncol 22: 3958-3964, 2004.

4. Yarden Y and Sliwkowski MX: Untangling the ErbB signalling network. Nat Rev Mol Cell Biol 2: 127-137, 2001.

5. Navolanic PM, Steelman LS and McCubrey JA: EGFR family signaling and its association with breast cancer development and resistance to chemotherapy (Review). Int J Oncol 22: 237-252, 2003.

6. Zhang YL, Yuan JQ, Wang KF, Fu XH, Han XR, Threapleton D, Yang ZY, Mao C and Tang JL: The prevalence of EGFR mutation in patients with non-small cell lung cancer: A systematic review and meta-analysis. Oncotarget 7: 78985-78993, 2016.

7. Brand TM, Iida M, Luthar N, Starr MM, Huppert EJ and Wheeler DL: Nuclear EGFR as a molecular target in cancer. Radiother Oncol 108: 370-377, 2013.

8. Lo HW, Ali-Seyed M, Wu Y, Bartholomeusz G, Hsu SC and Hung MC: Nuclear-cytoplasmic transport of EGFR involves receptor endocytosis, importin beta1 and CRM1. J Cell Biochem 98: 1570-1583, 2006.

9. Traynor AM, Weigel TL, Oettel KR, Yang DT, Zhang C, Kim K, Salgia R, Iida M, Brand TM, Hoang T, et al: Nuclear EGFR protein expression predicts poor survival in early stage non-small cell lung cancer. Lung Cancer 81: 138-141, 2013.

10. Hadzisejdić I, Mustać E, Jonjić N, Petković M and Grahovac B: Nuclear EGFR in ductal invasive breast cancer: Correlation with cyclin-D1 and prognosis. Mod Pathol 23: 392-403, 2010.

11. Yoo PS, Sullivan CA, Kiang S, Gao W, Uchio EM, Chung GG and $\mathrm{Cha} \mathrm{CH}$ : Tissue microarray analysis of 560 patients with colorectal adenocarcinoma: High expression of HuR predicts poor survival. Ann Surg Oncol 16: 200-207, 2009.

12. Richter I, Dvořák J, Urbanec M, Bluml A, Čermáková E, Bartoš J and Petera J: The prognostic significance of tumor epidermal growth factor receptor (EGFR) expression change after neoadjuvant chemoradiation in patients with rectal adenocarcinoma. Contemp Oncol (Pozn) 19: 48-53, 2015.

13. Li CF, Fang FM, Wang JM, Tzeng CC, Tai HC, Wei YC, Li SH, Lee YT, Wang YH, Yu SC, et al: EGFR nuclear import in gallbladder carcinoma: Nuclear phosphorylated EGFR upregulates iNOS expression and confers independent prognostic impact. Ann Surg Oncol 19: 443-454, 2012.

14. Molinari C, Matteucci F, Caroli P and Passardi A: Biomarkers and molecular imaging as predictors of response to neoadjuvant chemoradiotherapy in patients with locally advanced rectal cancer. Clin Colorectal Cancer 14: 227-238, 2015.

15. Smith FM, Reynolds JV, Miller N, Stephens RB and Kennedy MJ: Pathological and molecular predictors of the response of rectal cancer to neoadjuvant radiochemotherapy. Eur J Surg Oncol 32: 55-64, 2006.

16. Doger FK, Meteoglu I, Tuncyurek P, Okyay P and Cevikel H: Does the EGFR and VEGF expression predict the prognosis in colon cancer? Eur Surg Res 38: 540-544, 2006.

17. Rego RL, Foster NR, Smyrk TC, Le M, O'Connell MJ, Sargent DJ, Windschitl $\mathrm{H}$ and Sinicrope FA: Prognostic effect of activated EGFR expression in human colon carcinomas: Comparison with EGFR status. Br J Cancer 102: 165-172, 2010.

18. Garouniatis A, Zizi-Sermpetzoglou A, Rizos S, Kostakis A, Nikiteas $\mathrm{N}$ and Papavassiliou AG: FAK, CD44v6, c-Met and EGFR in colorectal cancer parameters: Tumour progression, metastasis, patient survival and receptor crosstalk. Int J Colorectal Dis 28: 9-18, 2013. 
19. Spano JP,Lagorce C,Atlan D, Milano G, Domont J, Benamouzig R, Attar A, Benichou J, Martin A, Morere JF, et al: Impact of EGFR expression on colorectal cancer patient prognosis and survival Ann Oncol 16: 102-108, 2005.

20. Wang YN, Wang H, Yamaguchi H, Lee HJ, Lee HH and Hung MC: COPI-mediated retrograde trafficking from the Golgi to the ER regulates EGFR nuclear transport. Biochem Biophys Res Commun 399: 498-504, 2010.

21. Lin SY, Makino K, Xia W, Matin A, Wen Y, Kwong KY, Bourguignon L and Hung MC: Nuclear localization of EGF receptor and its potential new role as a transcription factor. Nat Cell Biol 3: 802-808, 2001.

22. Lo HW, Hsu SC, Ali-Seyed M, Gunduz M, Xia W, Wei Y, Bartholomeusz G, Shih JY and Hung MC: Nuclear interaction of EGFR and STAT3 in the activation of the iNOS/NO pathway. Cancer Cell 7: 575-589, 2005.

23. Wang SC, Nakajima Y, Yu YL, Xia W, Chen CT, Yang CC, McIntush EW, Li LY, Hawke DH, Kobayashi R and Hung MC: Tyrosine phosphorylation controls PCNA function through protein stability. Nat Cell Biol 8: 1359-1368, 2006.
24. Dittmann K, Mayer C, Fehrenbacher B, Schaller M, Raju U, Milas L, Chen DJ, Kehlbach R and Rodemann HP: Radiation-induced epidermal growth factor receptor nuclear import is linked to activation of DNA-dependent protein kinase. J Biol Chem 280: 31182-31189, 2005.

25. Hoshino M, Fukui H, Ono Y, Sekikawa A, Ichikawa K, Tomita S, Imai Y, Imura J, Hiraishi H and Fujimori T: Nuclear expression of phosphorylated EGFR is associated with poor prognosis of patients with esophageal squamous cell carcinoma. Pathobiology 74: 15-21, 2007.

26. Hsu SC, Miller SA, Wang Y and Hung MC: Nuclear EGFR is required for cisplatin resistance and DNA repair. Am J Transl Res 1: 249-258, 2009.

This work is licensed under a Creative Commons Attribution-NonCommercial-NoDerivatives 4.0 International (CC BY-NC-ND 4.0) License. 